\title{
Experimental Results and Neural Prediction of Sequencing Batch Reactor Performance under Different Operational Conditions
}

\author{
E. R. Rene, K. S. Joo, and H. S. Park \\ Department of Civil and Environmental Engineering, University of Ulsan, San-29 Moogu-2 Dong, \\ Nam-Gu, Ulsan, 680-749, South Korea
}

Received 9 November 2006; revised 21 Feburary 2007; accepted 11 July 2007; published online 30 May 2008

\begin{abstract}
Three lab scale sequencing batch reactors (SBR) were simultaneously operated at different process conditions to understand the dynamics of organic and nitrogen removal from a synthetic wastewater source. The SBRs were operated continuously for 255 days at different $\mathrm{C} / \mathrm{N}$ ratio $(3-6)$, aeration time $(4-10 \mathrm{hr})$ and salt concentrations $(0.5-2 \%)$. The COD removal efficiencies under steady state operation were consistently greater than $80 \%$, while nitrogen removal efficiencies $(10-98 \%)$ were inhibited by high salt concentrations. Back propagation neural network was applied to model this experimental data using influent COD, influent nitrogen, salt concentration, aeration time, MLSS concentration and $\mathrm{C} / \mathrm{N}$ ratio as the input parameters to predict the performance parameters, viz., COD removal efficiency (COD-RE), total nitrogen removal efficiency (T-RE), $\mathrm{NH}_{4}{ }^{+}-\mathrm{N}, \mathrm{NO}_{3}{ }^{-}-\mathrm{N}_{\text {and }} \mathrm{NO}_{2}{ }^{-}-\mathrm{N}$ formed. The data points were randomized and divided into training $(190 \times 3)$ and testing set $(65 \times 3)$. The internal network parameters were selected using the $2^{k}$ full factorial design of experiments. The appropriate network topology for this system (6-12-5) was selected by estimating the best correlation coefficient $(R)$ value $(0.8482)$ achieved during prediction of the testing set. The result from this study showed that a neural network based model can be used as an efficient data driven model to predict the performance of a SBR unit.
\end{abstract}

Keywords: back propagation algorithm, organics and nitrogen removal, performance prediction, salt concentration, sensitivity analysis, sequencing batch reactors

\section{Introduction}

The concept to use biological treatment processes for simultaneous nitrification and denitrification steps in wastewater engineering has increasingly been improved over the recent years. One such treatment process is the Sequencing Batch Reactor (SBR), a well diversified, cost efficient and ecologically compactable treatment system for organics and nitrogen removal from wastewaters. The process occurs in a well defined sequential steps consisting of fill, react, settle, decant and idle. The wastewater is fed into the reactor during the fill stage and mixed with a well acclimatized biomass. A series of phenomenological reactions including BOD removal, nitrifycation, denitrification and phosphorous release/uptake occurs within the same reactor volume, thereby saving space and energy. The react step is usually arrayed to offer anaerobic, anoxic and aerobic conditions in certain time sequence and numbers. The microbes are separated during the settle stage and clarified water is withdrawn leaving behind the active biomass to accept the next batch of wastewater to be treated (Lee

\footnotetext{
* Corresponding author. Tel.: +82 52 2591050; fax: +82 522210152. E-mail address: parkhs@ulsan.ac.kr (H. S. Park).
}

ISSN: $1726-2135$ print/1684-8799 online

(C) 2008 ISEIS All rights reserved. doi:10.3808/jei.200800111 and Park, 1999). SBRs have been used extensively for COD, phosphate and nitrogen removal in both industrial and domestic wastewaters (Dangcong et al., 2004; Ganesh et al., 2006). A large number of studies have also been carried out using SBRs to identify the possible mechanisms of organic and nitrogen removal under low/high saline conditions (Dahl et al., 1997; Kargi and Dincer, 1997; Panswad and Anan, 1999; Dincer and Kargi, 2001; Uygur and Kargi, 2004; Uygur, 2006). Several structured models with their own limitations and assumptions have been proposed in the literature to simulate and predict the performance of SBR systems (Stephanopolous and San, 1984; Orhon et al., 1986; Artan et al., 1990; Ibrahim and Abasaeed, 1995; Furumai et al., 1999). Henze et al., 1987 developed a model that was capable of predicting the removal of organics, rate of nitrification and denitrification in suspended sludge systems. An extension of the same model was applied to simulate SBR by the research investigations of Artan et al. (1990). However the measurement of certain micro and macro kinetic parameters involves elaborate studies, sensitive instruments and numerous stochiometric equations. This makes the application of some of these existing models for SBRs very challenging. Additionally, most of the microbial medicated reactions are non linear with complex micro level interactions and are more severely affected by environmental conditions. Hence the best approach could be to formulate simple models that could overcome practical difficulties, yet that can appro- 
ximate all important events in the system. This is due to the inherent feature of black box modeling methodology; simplicity, fault and noise tolerance, plasticity property and versatility to process changes (Shahaf and Marom, 2001). Recently many literatures have been published using Artificial Neural Networks (ANN) for modeling biological wastewater treatment processes (Cote et al., 1995; Lee and Park, 1999; Gontarski et al., 2000; Cinar et al., 2006). ANNs have also been applied successfully for a wide variety of SBR based applications; process monitoring and control (Zhao and Kummel, 1995), soft sensors (Lee and Park, 1999) and online control of process variables (Cho et al., 2001). The neural network based modeling strategy focuses on ascertaining repeatable patterns that can be recognizable and predictable by proper training of a given data set. ANNs can map a set of non linear input patterns after learning a series of previous data without cognizing prior knowledge of the actual phenomenological steps involved within the process. Lee and Park (1999) created a feed forward back propagation network to predict $\mathrm{PO}_{4}{ }^{3-}, \mathrm{NH}_{4}{ }^{+}-\mathrm{N}$ and $\mathrm{NO}_{3}{ }^{-} \mathrm{N}$ concentration profiles using easily monitored variables like $\mathrm{pH}$, ORP and DO under aerobic and anaerobic phase operations in a SBR. Zhao et al. (1999) modeled the nutrient dynamics (nitrogen and phosphorous) in a SBR using activated sludge model No 2 (ASM2) and a hybrid simplified process model (SPM) coupled with ANNs. The SPM provided preliminary predictions of the system behavior while the neural networks were used to capture model prediction errors. The input parameters used in their study are influent $\mathrm{PO}_{4}{ }^{3-}$, $\mathrm{NH}_{4}^{+}-\mathrm{N}$, timer control signals (ON and OFF), COD, TKN, TN, temperature, $\mathrm{pH}$ and MLVSS.

In this paper we present the performance of three SBR units that were operated under different saline conditions $(0.5$, 1 and $2 \% \mathrm{NaCl}$ ) for a period of 255 days. The possibility of using ANN as a performance predictive tool to indicate the performance parameters namely, removal efficiencies of COD and total nitrogen, $\mathrm{NH}_{4}{ }^{+}-\mathrm{N}, \mathrm{NO}_{3}{ }^{-}-\mathrm{N}$ and $\mathrm{NO}_{2}^{-}-\mathrm{N}$ has been explored with a statistically significant approximation of the network parameters.

\section{Experimental: Material and Methods}

The heterogeneous seeding microbial population used in this study was obtained from a domestic sewage treatment plant near Ulsan, Korea. The nutrient media had the following composition: glucose $\left(625 \mathrm{mg} \cdot \mathrm{L}^{-1}\right), \mathrm{NH}_{4} \mathrm{Cl}\left(191 \sim 382 \mathrm{mg} \cdot \mathrm{L}^{-1}\right)$, $\mathrm{NaHCO}_{3}\left(594 \sim 1188 \mathrm{mg} \cdot \mathrm{L}^{-1}\right), \mathrm{KH}_{2} \mathrm{PO}_{4}\left(22 \mathrm{mg} \cdot \mathrm{L}^{-1}\right), \mathrm{MgSO}_{4}$. $7 \mathrm{H}_{2} \mathrm{O}\left(5 \mathrm{mg} \cdot \mathrm{L}^{-1}\right), \mathrm{CaCl}_{2}\left(0.4 \mathrm{mg} \cdot \mathrm{L}^{-1}\right), \mathrm{Na}_{2} \mathrm{MoO}_{4} \cdot 2 \mathrm{H}_{2} \mathrm{O}(1.26$ $\left.\mathrm{mg} \cdot \mathrm{L}^{-1}\right)$, and $\mathrm{NaCl}\left(5000,10000\right.$ and $\left.20000 \mathrm{mg} \cdot \mathrm{L}^{-1}\right)$. The $\mathrm{pH}$ of this synthetic wastewater was adjusted to $7 \pm 0.2$, while the temperature was held constant at $23 \pm 2^{\circ} \mathrm{C}$. All chemicals used were of analytical grade, purchased from Daejung Chemical and Metals Co. Ltd.

The schematic of the experimental setup is shown in Figure 1 . The clarified supernatant (4 liters) was collected from the sampling port at the end of every settle and decant step to measure the different water quality parameters mentioned in this study. The solid retention time was changed during different phases of operational conditions from 20 to 100 days by wasting mixed liquor suspended solids at the end of the aeration step. The operation of peristaltic pump, stirrer and aerator were computer controlled using a $\mathrm{C}^{++}$based program (SBR control system, Korea). The different operational conditions and time steps used in this study are given in Table 1. These conditions were applied in parallel to the three SBR units that were operated at a salt concentration of $0.5,1$ and $2 \%$ respectively. Experiments were carried out till steady state removal of both organics and nitrogen were achieved.

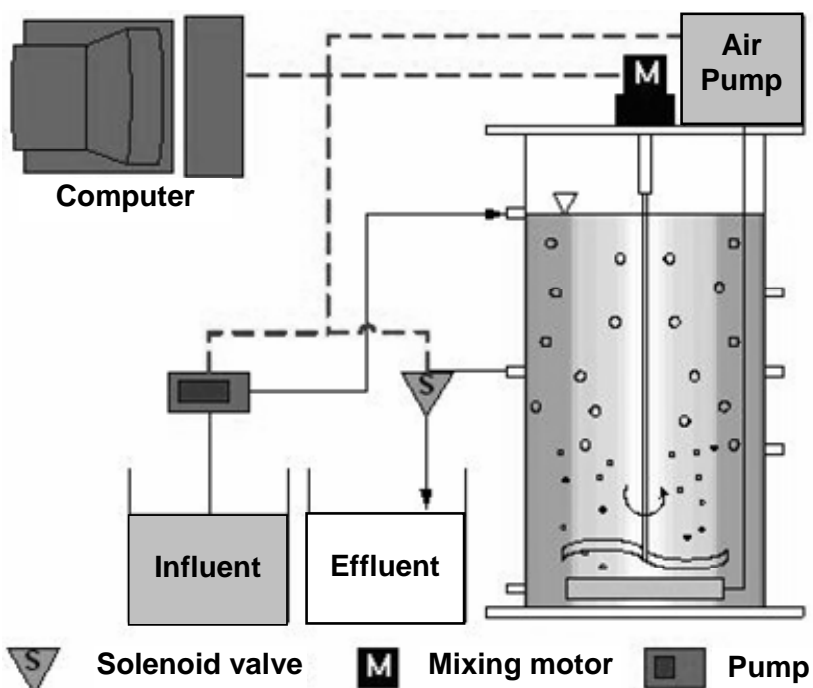

Figure 1. Schematic of an experimental SBR unit.

Table 1. Experimental Scheme of SBR Operation

\begin{tabular}{|c|c|c|c|c|c|c|c|}
\hline \multirow{2}{*}{ Process condition } & \multirow{2}{*}{$\mathrm{C} / \mathrm{N}$ ratio } & \multirow{2}{*}{ Cycle time } & \multicolumn{4}{|c|}{ Time of operation (hr) } & \multirow{2}{*}{$\begin{array}{l}\text { Operation } \\
\text { time (day) }\end{array}$} \\
\hline & & & Anoxic & Aerobic & Anaerobic & Settle and decant & \\
\hline Acclimatization & 6 & 12 & 2 & 4 & 4 & 2 & 36 \\
\hline A & 6 & 24 & 3 & 10 & 9 & 2 & 100 \\
\hline $\mathrm{B}$ & 6 & 24 & 2 & 6 & $14^{*}$ & 2 & 40 \\
\hline $\mathrm{C}$ & 6 & 12 & 2 & 4 & 4 & 2 & 36 \\
\hline $\mathrm{D}$ & 3 & 12 & 2 & 4 & 4 & 2 & 43 \\
\hline
\end{tabular}

* with intermittent mixing 
The effluent quality (treated saline wastewater) from the three SBR was monitored regularly for the COD, total nitrogen, $\mathrm{NH}_{4}{ }^{+}-\mathrm{N}, \mathrm{NO}_{3}{ }^{-} \mathrm{N}, \mathrm{NO}_{2}{ }^{-}-\mathrm{N}$ and MLSS concentrations. All samples were filtered using a $0.45 \mu \mathrm{m}$ filter prior to analysis. Samples collected during week ends were acidified by the addition of $0.2 \mathrm{ml}$ concentrated $\mathrm{H}_{2} \mathrm{SO}_{4}$ to $100 \mathrm{ml}$ of the sample and stored at $4^{\circ} \mathrm{C}$ in a refrigerator before use. COD, MLSS and total nitrogen concentrations were measured according to the procedure described in Standard Methods (APHA, 1995). A standard kit (Hach, DR 2000) and spectrophotometric method was used to determine concentrations of $\mathrm{NH}_{4}{ }^{+}-\mathrm{N}, \mathrm{NO}_{3}{ }^{-} \mathrm{N}$ and $\mathrm{NO}_{2}{ }^{-} \mathrm{N}$ at their respective $\lambda_{\max }(425,500$ and $507 \mathrm{~nm})$. The influent wastewater quality was monitored twice a week for both organics and nitrogen content. All analyses were carried out in duplicate and their arithmetic mean value was used for analysis of the results and neural network modeling. The variations in these values were found to be less and negligible $(<1 \%)$.

\section{ANN Modeling}

Artificial neural networks are powerful data driven modeling tools that has the ability to capture and represent complex input/output relationships. ANNs consists of a system of simple interconnected processing element called neurons. This gives the ability to model any non-linear process through a set of unidirectional weighted connections. The neuron accepts input from single or multiple sources and produces output by a simple calculating process guarded by a non-linear transfer function. A simple three-layered network with an input layer, hidden layer and output layer is shown in Figure 2. The input layer consists of a set of neurons $\mathrm{N}_{\mathrm{I}}$, each representing an input parameter and propagates the raw information to the neuron in the hidden layer $\left(\mathrm{N}_{\mathrm{H}}\right)$, which in turn transmits them, to the neurons in the output layer $\left(\mathrm{N}_{\mathrm{O}}\right)$. Each layer consists of several neurons and the layers are connected by the connection weights $\left(\mathrm{W}_{\mathrm{ij}}{ }^{1}\right.$ and $\left.\mathrm{W}_{\mathrm{ij}}{ }^{2}\right)$. The most commonly used transfer function is the sigmoid function as described by

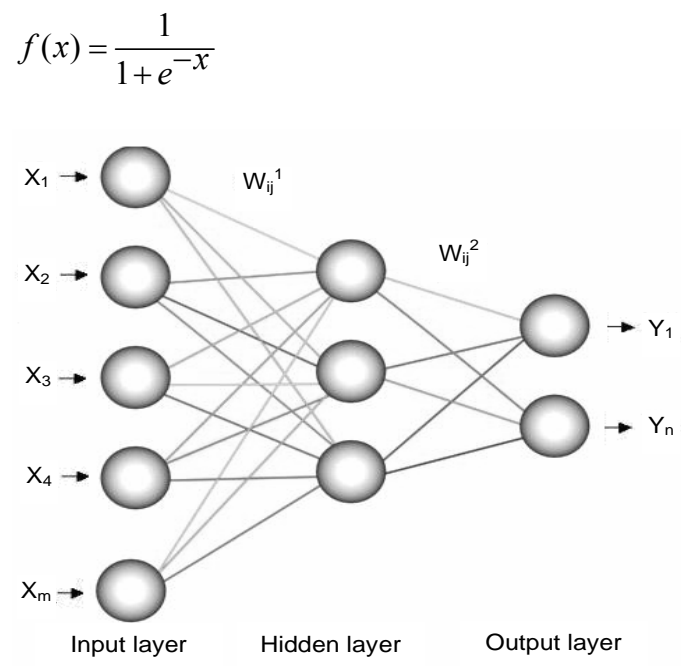

Figure 2. Basic structure of an ANN model.
This produces output in the range of $0-1$ and introduces non-linearity into the network, which gives the power to capture nonlinear relationships. The back propagation network is the most prevalent supervised ANN learning model (Rumelhart et al., 1986). It uses the gradient descent algorithm to correct the weights between interconnected neurons (Maier and Dandy, 2001). During the learning process of the network, the algorithm computes the error between the predicted and specified target values at the output layer. The error function at the output layer can be defined by:

$\mathrm{E}=\frac{1}{2} \sum\left(O_{d}-O_{p}\right)^{2}$

\subsection{Data Pre-processing and Division}

The data points from the three SBR systems, operated at salt concentrations of $0.5,1$ and $2 \%$ were randomized and commingled sequentially to form a combined data set consisting of 765 values for each parameter considered in this study. Randomization was done to obtain a spatial distribution of the data, which accounts for both steady state and unsteady state operations within the SBR system. The data was also normalized and scaled (Equation 3 ) to the range of 0 to 1 , so as to suit the transfer function in the hidden (sigmoid) and output layer (linear). More comprehensible information on different types of transfer function, algorithms, and internal parameter used for developing ANN models are given by Haykin (1999) and Hoskins and Himmelblau (1999):

$\hat{X}=\frac{X-X_{\min }}{X_{\max }-X_{\min }}$

This processed data was later divided into two sets: training and testing. About 75\% (570) of the data points were used for training the network, while the remaining $25 \%$ (195) were used for testing the developed network.

\subsection{Model Inputs and Outputs}

The input vectors to the network were the easily monitored parameters, namely input COD concentration $\left(\mathrm{X}_{1}\right)$, inlet total nitrogen $\left(\mathrm{X}_{2}\right), \mathrm{C} / \mathrm{N}$ ratio $\left(\mathrm{X}_{3}\right)$, aeration time $\left(\mathrm{X}_{4}\right)$, MLSS concentration $\left(\mathrm{X}_{5}\right)$ and salt concentration $\left(\mathrm{X}_{6}\right)$. The outputs to the ANN model were COD removal efficiency $\left(\mathrm{Y}_{1}\right)$, nitrogen removal efficiency $\left(\mathrm{Y}_{2}\right), \mathrm{NH}_{4}-\mathrm{N}\left(\mathrm{Y}_{3}\right), \mathrm{NO}_{3}-\mathrm{N}\left(\mathrm{Y}_{4}\right)$, and $\mathrm{NO}_{2}-\mathrm{N}$ $\left(\mathrm{Y}_{5}\right)$, respectively. The range of these parameter values used for network training $\left(\mathrm{N}_{\mathrm{Tr}}\right)$ and testing $\left(\mathrm{N}_{\mathrm{Te}}\right)$ is shown in Table 2. This modeling work was carried out using the shareware version of the neural network and multivariable statistical modeling software, NNMODEL (Version 1.4, Neural Fusion, NY). The experimental data were pre-processed by using the "randomize rows" function in the software (NeuroSolutions for Excel, Version 4.3).

\subsection{Internal Network Parameters}

A good network architecture requires proper selection of 
sensitive parameters like: number of hidden layers, the number of neurons in the hidden layer $\left(\mathrm{N}_{\mathrm{H}}\right)$, the activation function $f(x)$, the learning rate of the network $(\eta)$, epoch size $(\varepsilon)$, momentum term $(\alpha)$ and training cycles $\left(T_{C}\right)$. The network architecture has to be optimized to reduce computer processing, achieve good predictability and avoid overfitting.

Table 2. Ranges of Values of Input and Output Parameters Used for Training and Testing the Network

\begin{tabular}{lcccc}
\hline \multirow{2}{*}{ Parameters } & \multicolumn{2}{c}{$\begin{array}{c}\text { Training data, } \\
\mathrm{N}_{\mathrm{Tr}}=570\end{array}$} & \multicolumn{2}{c}{$\begin{array}{c}\text { Testing data, } \\
\mathrm{N}_{\mathrm{Te}}=195\end{array}$} \\
\cline { 2 - 5 } & $\mathrm{Min}$ & $\mathrm{Max}$ & $\mathrm{Min}$ & $\mathrm{Max}$ \\
\hline Input: & & & & \\
COD concentration, mg/L & 41.12 & 300 & 41.12 & 300 \\
Inlet total nitrogen, mg/L & 11 & 100 & 11 & 100 \\
C/N ratio & 3 & 6 & 3 & 6 \\
Aeration time, hr & 4 & 10 & 4 & 10 \\
MLSS concentration, & 1647.7 & 9432.4 & 1746.7 & 9279.4 \\
mg/L & 0.5 & 2 & 0.5 & 2 \\
Salt concentration, \% & & & & \\
\hline Output: & 72.2 & 100 & 83.2 & 100 \\
COD removal & & & & \\
efficiency, \% & 9 & 98.9 & 9.56 & 98.6 \\
$\mathrm{Nitrogen}$ removal & & & & \\
efficiency, \% & 0.02 & 18.38 & 0.05 & 20.13 \\
$\mathrm{NH}_{4}{ }^{-}-\mathrm{N}, \mathrm{mg} / \mathrm{L}$ & 0.4 & 29 & 0.4 & 28 \\
$\mathrm{NO}_{3}^{-}-\mathrm{N}, \mathrm{mg} / \mathrm{L}$ & 0.0004 & 20.42 & 0.0014 & 20.25 \\
$\mathrm{NO}_{2}^{-}-\mathrm{N}, \mathrm{mg} / \mathrm{L}$ & & &
\end{tabular}

The learning rate $(\eta)$ and momentum $(\alpha)$ can play an important role in the convergence of the network. The value of $\eta$ of a network affects the size of steps taken in the weight space (Maier and Dandy, 1998). If $\eta$ is too small, the algorithm would take more time to converge. The momentum term $(\alpha)$ accelerates the convergence of the error during the learning process by adding a fraction to the precious weight update. The values of $\eta$ and $\alpha$ varies between 0 and 1, and is normally estimated by trial and error (Maier and Dandy, 1998). Initially, network training based on a trail and error approach was used to identify the best suitable range of these parameters that can be used in factorial design simulations. The specifications of network parameters used for training is shown in Table 3. The time required for the networks training was in the range of 1 to $4 \mathrm{~min}$. A detailed study on the effect of internal network parameter on the performance of BPNN and the procedure involved in selecting the best network topology has been described elsewhere (Maier and Dandy, 1998).

\subsection{Selecting the Best Model Architecture Using Factorial Design}

Factorial design of the network parameter was chosen to replace the conventional trial and error approach in determining the optimal or best values during network training. Factorial designs are widely used where several factors are involved to understand the main and interactions effect on the final response. In factorial experiments, a number of independent variables are altered within a single run/simulation. The 2-level full factorial design, which is most popular, includes all possible factor combinations at two levels, low and high, for each of the factors. It is a powerful tool for understanding the complex processes whose detailed mechanisms are unknown and for describing factor interactions in multi factor systems. The effect of a factor is defined to be the change in response produced by a change in the level of the factor. This is frequently called a main effect because it refers to the primary factors of interest in the experiment (Montgomery, 1991). Moreover, full factorial design allows the effects of a factor to be estimated at several levels of other factors, yielding conclusions that are valid over a range of experimental conditions. In this study, the four parameters $(k=4)$ namely $N_{H}, T_{C}, \eta$, and $\alpha$ were chosen between their minimum and maximum levels as described earlier. The response was the correlation coefficient (R), which substantially determines the closeness of prediction between the desired and predicted output from the network. This is given by:

$$
R=\frac{\sum X Y-\frac{\sum X \sum Y}{N}}{\sqrt{\left(\sum X^{2}-\frac{\left(\sum X\right)^{2}}{N}\right)\left(\sum Y^{2}-\frac{\left(\sum Y\right)^{2}}{N}\right)}}
$$

where $X$ is the experimental value, $Y$ is the predicted value from the model and $N$ is the total number of observations. Simulations were also done at the center point of the network parameters, which was used for calculating the errors. Furthermore, for the testing data set, the total mean squared error (RMSE) was computed according to the formulae given by Elias et al. (2006). The effects of the main variable and their mutual interactions were analyzed using the $F$ (Fisher's $F$ value), $P$ (Probability value) and $T$ (Student ' $t$ ' test) values. Table 4 shows the $2^{4}$ factorial design carried out for estimating the best network topology along with the observed $R$ value in each runs. A total of 17 runs were performed to arrive at the best predictive network. This statistically significant experimental procedure reduces the number of trials and provides more information on the effects of individual factors through the main effects plot (Box et al., 1978; Montgomery, 1991). Factorial design analysis and plots were obtained from the statistical software MINITAB (Version 12.2, PA, USA).

Table 3. Neural Network Parameters Used during Training

\begin{tabular}{ll}
\hline Parameter & Value \\
\hline Hidden neurons $\left(\mathrm{N}_{\mathrm{H}}\right)$ & $6-12$ \\
Training cycles, $T_{c}$ & $20000-50000$ \\
Learning rate, $\eta$ & $0.1-0.9$ \\
Momentum, $\alpha$ & $0.1-0.9$ \\
Epoch size, $\varepsilon$ & 100 \\
Confidence interval & $95 \%$ \\
Error tolerance & 0.0001 \\
\hline
\end{tabular}




\section{Results and Discussions}

\subsection{Experimental}

The regular experimentation with the SBR systems was investigated for a period of 255 days at three different salt concentrations, viz., $0.5,1$ and $2 \%$. The time course profiles of influent $\mathrm{COD}$ and nitrogen concentration together with the $\mathrm{COD}$ and nitrogen removal efficiencies, $\mathrm{NH}_{4}{ }^{+}-\mathrm{N}, \mathrm{NO}_{3}{ }^{-}-\mathrm{N}$ and $\mathrm{NO}_{2}-\mathrm{N}$ concentrations are shown in Figures 3 and 4 for the SBR system operated at a salt concentration of $0.5 \%$. Similar profiles were obtained for the other two reactors. During the initial 36 days, the reactors were subjected to low salt concentrations $(0.5 \%)$ operated at low COD $(<100 \mathrm{mg} / \mathrm{L})$ and nitrogen concentrations with a cycle time of 12 hours. It could be seen that the performance of the systems in terms of the COD and total nitrogen removal increased in small fluctuating time steps and varied between 70 and $100 \%$, and 50 and $80 \%$, respectively. From Figure 4, it is also clearly evident that the nitrification and denitrification steps occurred quickly within these three reactors. The SRT during different operational conditions were maintained between 20 to 100 days by sludge wasting after the aeration step. On the $37^{\text {th }}$ day, experiments were carried out under the condition A (aeration time $=10$ hours), which corresponds to influent COD and nitrogen concentrations of 300 and $50 \mathrm{mg} / \mathrm{L}$, respectively. From this time, the $\mathrm{NO}_{3}{ }^{-} \mathrm{N}$ concentration in the effluent also gradually increased peaking at about $25 \mathrm{mg} / \mathrm{L}$ on the $75^{\text {th }}$ day. However the nitrogen removal profile under this condition varied widely in the three reactors depending on the inhibition effects caused by saline conditions. The nitrogen removal efficiencies varied between, 28 and $80 \%, 30$ and $85 \%$ and 10 and $80 \%$ in three reactors. It was also observed that nitrate in the wastewater was utilized quickly the denitrifying microbial community wi- thin the reactor. Due to depletion of carbon source, a decline in the denitrification rate was observed. During this phase, the COD removal pattern was nearly similar in the three reactors, and was above $95 \%$ irrespective of the salt concentrations. In this study, it was observed that the MLSS concentration gradually decreased in all the reactors, when the SRT was 40 and 20 days (data not shown). This invariably affected the performance of the reactors after 100 days of continuous operation. Moussa et al. (2005) operated two laboratory scale SBR systems at a solids retention time (SRT) of 30 and 100 days, having a $6 \mathrm{hr}$ cycle length to calibrate and validate a model for nitrification, heterotrophic growth and predation in activated sludge. Their results showed that increasing the SRT increases the biomass concentration, while the volumetric ammonia and nitrite oxidation rate followed a saturation curve after 40 days SRT.

The removal efficiencies for COD and nitrogen were nearly 80 and $50 \%$ respectively. Hence from the $137^{\text {th }}$ day (conditions B-D), sludge wasting was avoided to increase the concentration of biomass within the reactors and SRT thus maintained at 100 days. When experiments were conducted at the condition $C$, that corresponds to $2 / 4 / 4 / 2$ hours of time sequenced steps at a $\mathrm{C} / \mathrm{N}$ ratio of 6 , the performance of the reactors were consistently higher than the previous stages of operation. The COD and nitrogen removal efficiencies were greater than $95 \%$. Similar results have been demonstrated for treating piggery wastewaters with high COD, nitrogen and phosphorous removals (>98\%) (Tilche et al., 1999). The $\mathrm{C} / \mathrm{N}$ ratio and the aeration times are very important parameter for successful operation of any SBR system. During the next 43 days of operation (condition $\mathrm{D}$ ) the $\mathrm{C} / \mathrm{N}$ ratio was decreased to 3 holding the aeration time at 4 hours. The responses in the reactors were a sudden drop in the nitrogen removal profiles.

Table 4. Network Internal Parameters and Corresponding Correlation Coefficients after Model Testing

\begin{tabular}{|c|c|c|c|c|c|c|c|c|c|c|}
\hline \multirow[b]{2}{*}{ Run No. } & \multirow[b]{2}{*}{$\mathrm{N}_{\mathrm{h}}$} & \multirow[b]{2}{*}{$T_{c}$} & \multirow[b]{2}{*}{$\eta$} & \multirow[b]{2}{*}{$\alpha$} & \multicolumn{6}{|c|}{ Correlation coefficient (R) } \\
\hline & & & & & $\begin{array}{c}\text { COD-RE } \\
\left(\mathrm{X}_{1}\right)\end{array}$ & $\begin{array}{c}\text { N-RE } \\
\left(\mathrm{X}_{2}\right)\end{array}$ & $\begin{array}{c}\mathrm{NH}_{4}^{+}-\mathrm{N} \\
\left(\mathrm{X}_{3}\right)\end{array}$ & $\begin{array}{c}\mathrm{NO}_{3}{ }^{-}-\mathrm{N} \\
\left(\mathrm{X}_{4}\right)\end{array}$ & $\begin{array}{c}\mathrm{NO}_{2}{ }^{-}-\mathrm{N} \\
\left(\mathrm{X}_{5}\right)\end{array}$ & Average \\
\hline 1 & 6 & 20000 & 0.1 & 0.1 & 0.7457 & 0.7565 & 0.6855 & 0.7697 & 0.7848 & 0.7484 \\
\hline 2 & 12 & 20000 & 0.1 & 0.1 & 0.8159 & 0.7909 & 0.7196 & 0.7984 & 0.8123 & 0.7874 \\
\hline 3 & 6 & 50000 & 0.1 & 0.1 & 0.7469 & 0.7565 & 0.6843 & 0.7697 & 0.7849 & 0.7484 \\
\hline 4 & 12 & 50000 & 0.1 & 0.1 & 0.7129 & 0.9074 & 0.8179 & 0.9014 & 0.9012 & 0.8482 \\
\hline 5 & 6 & 20000 & 0.9 & 0.1 & 0.5546 & 0.7329 & 0.6058 & 0.7702 & 0.8026 & 0.6932 \\
\hline 6 & 12 & 20000 & 0.9 & 0.1 & 0.6532 & 0.7558 & 0.5940 & 0.7647 & 0.7734 & 0.7082 \\
\hline 7 & 6 & 50000 & 0.9 & 0.1 & 0.4698 & 0.7358 & 0.6191 & 0.7683 & 0.799 & 0.6784 \\
\hline 8 & 12 & 50000 & 0.9 & 0.1 & 0.6529 & 0.7599 & 0.5866 & 0.7690 & 0.7746 & 0.7086 \\
\hline 9 & 6 & 20000 & 0.1 & 0.9 & 0.7349 & 0.7909 & 0.6648 & 0.8118 & 0.8543 & 0.7713 \\
\hline 10 & 12 & 20000 & 0.1 & 0.9 & 0.8197 & 0.7740 & 0.7278 & 0.777 & 0.7836 & 0.7764 \\
\hline 11 & 6 & 50000 & 0.1 & 0.9 & 0.6845 & 0.7696 & 0.7161 & 0.791 & 0.8346 & 0.7591 \\
\hline 12 & 12 & 50000 & 0.1 & 0.9 & 0.6974 & 0.8033 & 0.6998 & 0.8337 & 0.8760 & 0.7820 \\
\hline 13 & 6 & 20000 & 0.9 & 0.9 & 0.3411 & 0.664 & 0.7406 & 0.7848 & 0.7462 & 0.6553 \\
\hline 14 & 12 & 20000 & 0.9 & 0.9 & 0.531 & 0.7515 & 0.7227 & 0.7884 & 0.8157 & 0.7218 \\
\hline 15 & 6 & 50000 & 0.9 & 0.9 & 0.3327 & 0.6626 & 0.7446 & 0.7885 & 0.7587 & 0.6574 \\
\hline 16 & 12 & 50000 & 0.9 & 0.9 & 0.494 & 0.744 & 0.7291 & 0.7967 & 0.8152 & 0.7158 \\
\hline 17 & 9 & 35000 & 0.5 & 0.5 & 0.3761 & 0.7759 & 0.7535 & 0.789 & 0.8059 & 0.7000 \\
\hline
\end{tabular}




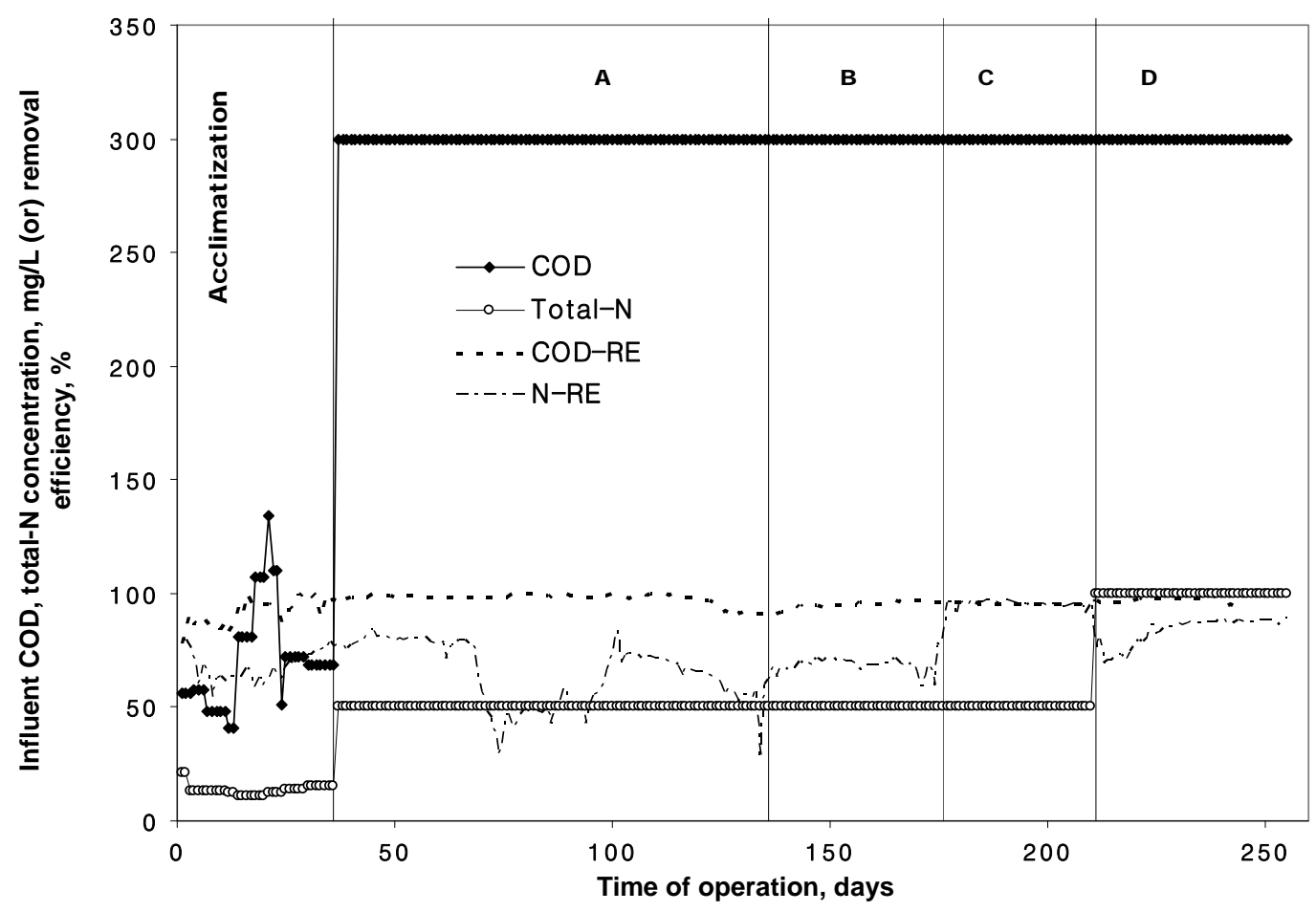

Figure 3. Time course profiles of COD and total nitrogen removal in SBR system operated at a salt concentration of $0.5 \%$ (RE - Removal efficiency; A, B, C, D - Experimental phases of SBR operation).

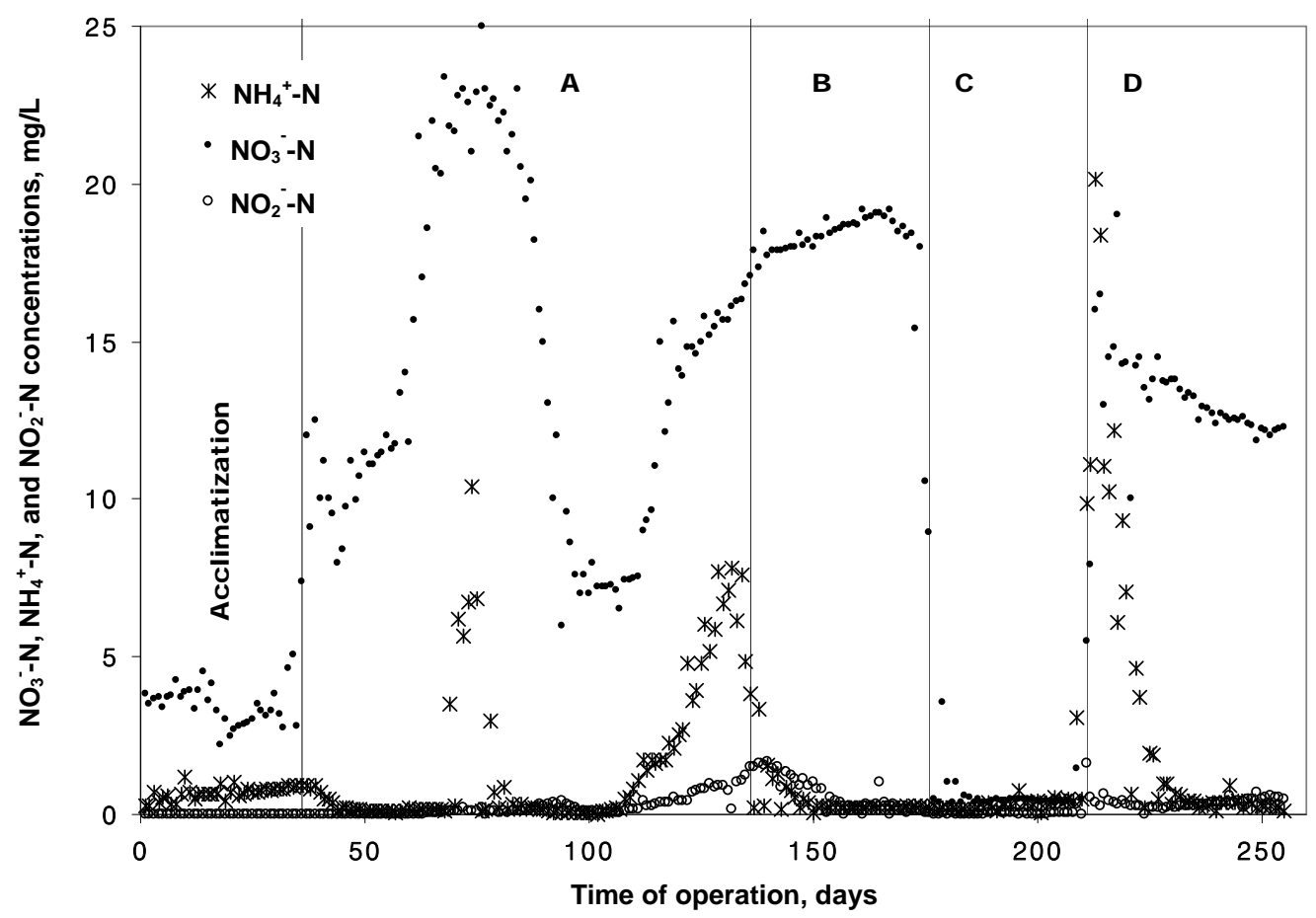

Figure 4. Time course profiles of $\mathrm{NH}_{4}{ }^{+}-\mathrm{N}, \mathrm{NO}_{3}{ }^{-}-\mathrm{N}$ and $\mathrm{NO}_{2}{ }^{-}-\mathrm{N}$ in $\mathrm{SBR}$ system operated at a salt concentration of $0.5 \%$ (A, B, C, D - Experimental phases of SBR operation). 
The removal efficiency dropped to as low as $20 \%$ in the third reactor. The peaking of $\mathrm{NO}_{2}^{-}-\mathrm{N}$ was observed in two reactors ( $\mathrm{NaCl}: 1$ and $2 \%$ ) due to nitrite accumulations under oxygen limiting conditions. The overall results suggest that, the COD removal efficiencies remained largely unaffected due to the changes in operational conditions, especially the SRT variations between 20 and 100 days, while nitrogen removal efficiencies varied depending on the initial salt concentrations.

Table 5. Analysis of Variance and Effect of Factors on the R Values Observed after Model Testing

\begin{tabular}{lcc}
\hline Source & \multicolumn{2}{c}{ Statistical coefficients } \\
\cline { 2 - 3 } & $\mathrm{F}$ & $\mathrm{P}$ \\
\hline Analysis of variance: & & \\
Main effects & 4000.00 & 0.004 \\
2-way interactions & 677.43 & 0.029 \\
3-way interactions & 3000 & 0.013 \\
4-way interactions & 92.78 & 0.066 \\
\hline Factor: & $\mathrm{T}$ & $\mathrm{P}$ \\
$N_{h}$ & 165.38 & 0.004 \\
$T_{c}$ & 17.59 & 0.036 \\
$\eta$ & -335.20 & 0.002 \\
$\alpha$ & -40.06 & 0.016 \\
\hline
\end{tabular}

\subsection{ANN Modeling}

\subsubsection{Network Architecture}

The ANN based model was trained and tested adequately with the experimental data $(255 \times 3)$ and evaluated by their correlation coefficient, $R$ between the experimentally observed and predicted outputs from the network. The best network was chosen based on high averaged $R$ values observed for a particular parameter setting during model testing. It is quite evident from Table 4 that parameter setting at run 4 gave high $R$ value than other runs specified by the factorial design. Statistical analysis in the form of analysis of variance (ANOVA) was performed on the network parameters and their corresponding $F, P$ and $T$ values were obtained (Table 5). As indicated by the high $F$ and low $P$ values $(4000,0.004)$, the main effects of the variables was found to be highly significant than the interaction effects. Among the linear effects, the number of neurons in the hidden layer $\left(N_{h}\right)$ and the learning rate $(\eta)$ had a strong positive $(T: 165.38, F: 0.004)$ and negative $(T$ : $-335.2, F: 0.002$ ) influence on the $R$ values, in comparison to the other internal network parameters. This main effects plot is shown in Figure 5. Increasing the number of neurons in the hidden layer from low to high levels (6 to 12) in the hidden layer increased the training capability of the network in the positive direction (high $R$ value), while the reverse occurred when the learning rate was increased from 0.1 to 0.9 . On the other hand, both the training count and momentum term did not show any significant influence in improving the training performance. Among the interaction effects, the combinations of number of neurons in the hidden layer, leaning rate and momentum term showed satisfactory levels of positive performance as compared to the other combinations ( $T: 93.52, F$ :
$0.007)$. The best network architecture is $6-12-5$ as indicated by run 4 in the ANN modeling runs. The $R$ values observed for difference performance parameters during network training and testing is shown in Table 6. The results from this study indicate that low learning rate $(0.1)$, low momentum term (0.1) and a training count of 50000 with 12 neurons in the hidden layer are favorable values of the internal network parameters.

Table 6. Correlation Coefficient, $\mathrm{R}$ and RMSE Values during Network Training and Testing

\begin{tabular}{lccc}
\hline Parameters & $\begin{array}{c}\mathrm{R} \text { value during } \\
\text { training }\end{array}$ & $\begin{array}{c}\mathrm{R} \text { value during } \\
\text { testing }\end{array}$ & $\begin{array}{c}\text { RMSE value } \\
\text { during testing }\end{array}$ \\
\hline $\mathrm{COD}-\mathrm{RE}$ & 0.7363 & 0.7129 & 2.303 \\
$\mathrm{~N}-\mathrm{RE}$ & 0.8989 & 0.9074 & 128.201 \\
$\mathrm{NH}_{4}^{+}-\mathrm{N}$ & 0.8601 & 0.8179 & 30.118 \\
$\mathrm{NO}_{3}{ }^{-}-\mathrm{N}$ & 0.8919 & 0.9014 & 38.959 \\
$\mathrm{NO}_{2}{ }^{-}-\mathrm{N}$ & 0.8777 & 0.9012 & 34.105 \\
\hline
\end{tabular}

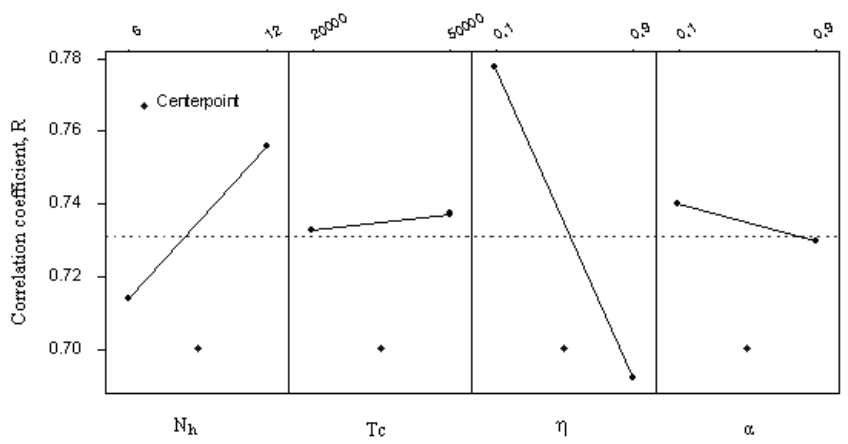

Figure 5. The main effects plot of internal network parameters on the $\mathrm{R}$ value during training of model.

\subsubsection{Predictive Capability and Sensitivity Analysis of the Developed Model}

The performance indices namely removal efficiencies of $\mathrm{COD}$ and nitrogen together with $\mathrm{NH}_{4}{ }^{+}-\mathrm{N}, \mathrm{NO}_{3}{ }^{-}-\mathrm{N}$ and $\mathrm{NO}_{2}{ }^{-} \mathrm{N}$ were predicted directly from the model input variables. A comparison of the experimental and model predicted values of these variables are shown in Figure 6 for the trained network $(190 \times 3)$. These figures collectively exhibit good learning capability of the trained network. Furthermore the network was able to map the low and high peaks of the randomized data points with a high degree of success as evident from their $R$ values. However, some of the data points (COD RE $<85 \%$, $\mathrm{NH}_{4}{ }^{+}-\mathrm{N}>15 \mathrm{mg} / \mathrm{L}, \mathrm{NO}_{3}{ }^{-} \mathrm{N}>22 \mathrm{mg} / \mathrm{L}$ and $\left.\mathrm{NO}_{2}{ }^{-} \mathrm{N}>15 \mathrm{mg} / \mathrm{L}\right)$ were not mapped properly by the network. Corroborating this behavior are low nitrogen removal efficiencies at a salt concentration of 1 and $2 \%$, nitrate accumulation and $\mathrm{NO}_{2}{ }^{-} \mathrm{N}$ formation under low DO concentrations. Nitrite accumulation has shown to cause a toxic effect linked to $\mathrm{pH}$ effects on biomass, specifically ammonia oxidizers (Antoniou et al., 1990; Moussa et al., 2003). This decreased nitrogen removal profiles have caused a significant impact on the networks generalization pattern while mapping these variables. Once the network 


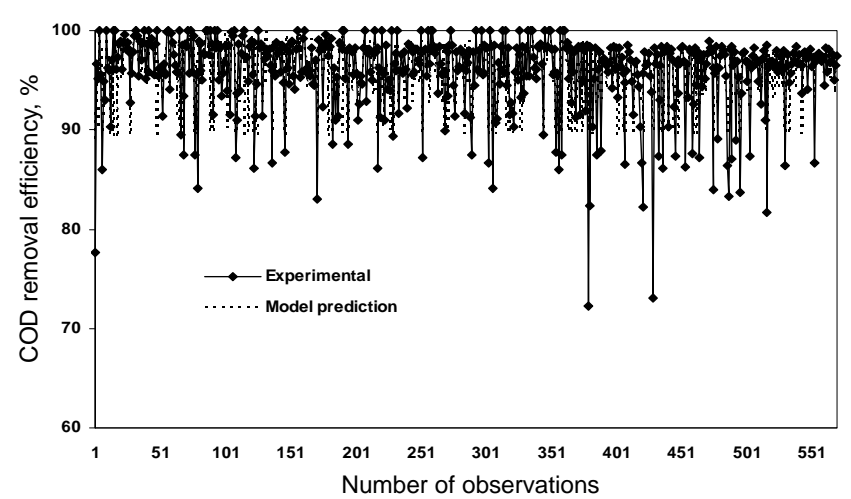

(a)

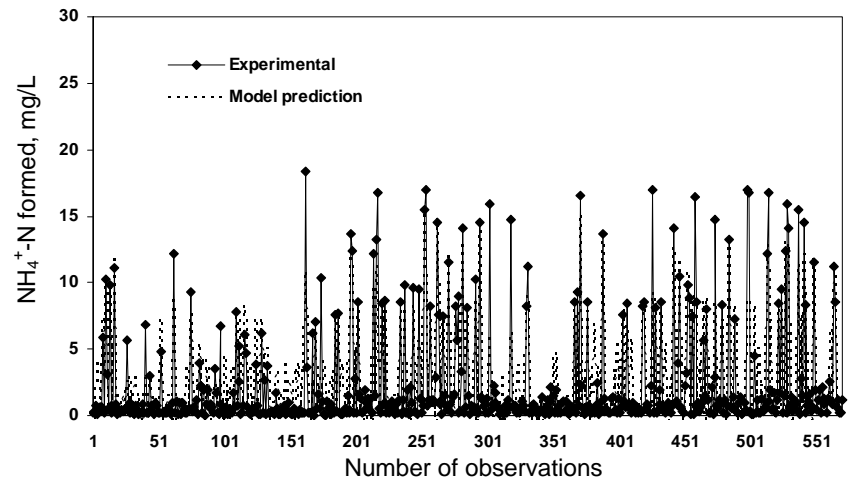

(c)

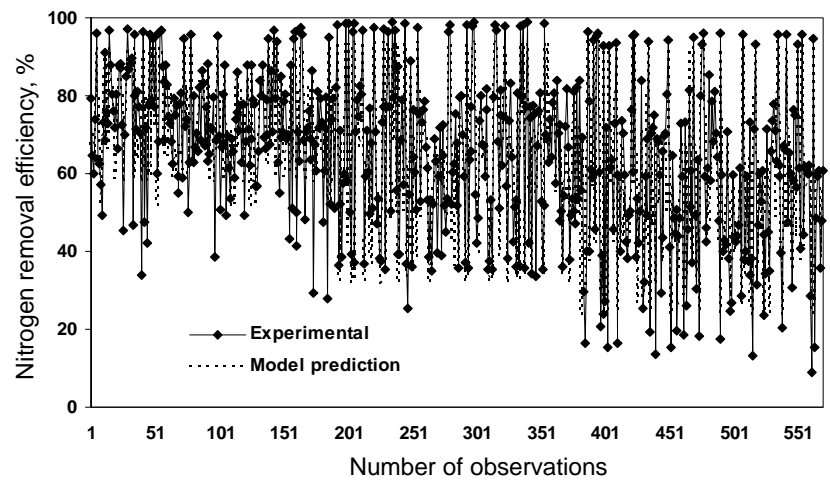

(b)

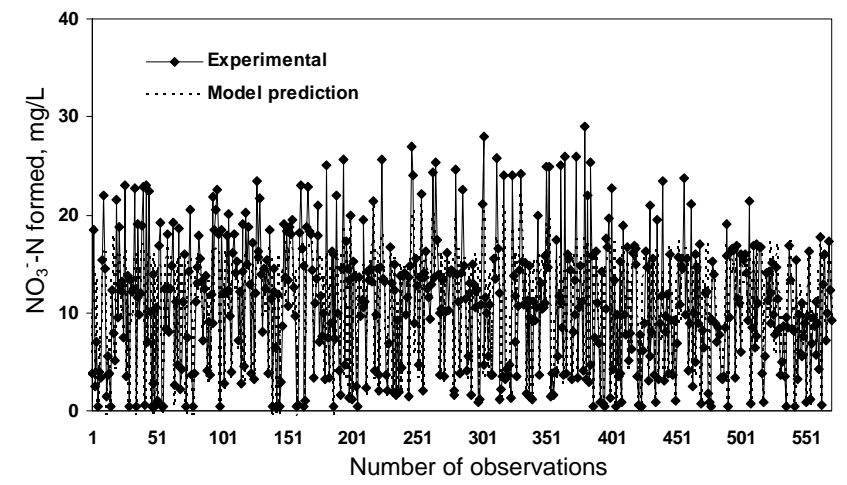

(d)

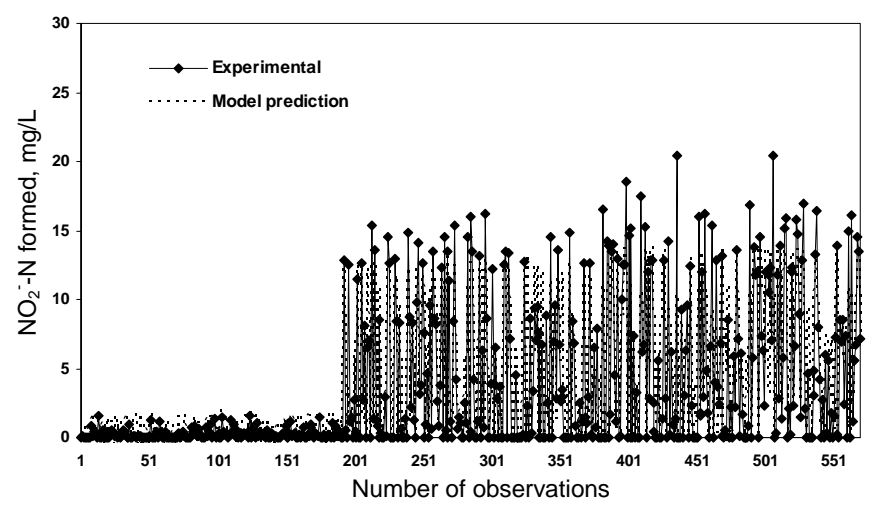

(e)

Figure 6. Predictive capability of the ANN model during network training.

was trained adequately, the test data $(65 \times 3)$ was used to evaluate the performance of the model. These results are shown in Figure 7. The data points are representative of the three reactors operated under different saline concentrations. Compared to the training data, the test one showed high correlation with the experimentally observed values.

Anew to this, by estimating the Absolute Average Sensitivity (AAS), a sensitivity analysis was carried out using the software NNMODEL to identify the most influential parameter that affects the reactors performance. The sensitivity is calculated by summing the changes in the output variables caused by moving the input variables by a small amount over the entire training set (Zurada et al., 1994). The absolute value average sensitivity matrix $S_{k i, a b s}$ is defined as:

$S_{k i, a b s}=\frac{\sum_{p=1}^{p} S_{k i}^{(p)}}{p}$

The result from sensitivity analysis is shown in Figure 8. It could be seen that MLVSS concentration plays a major role 


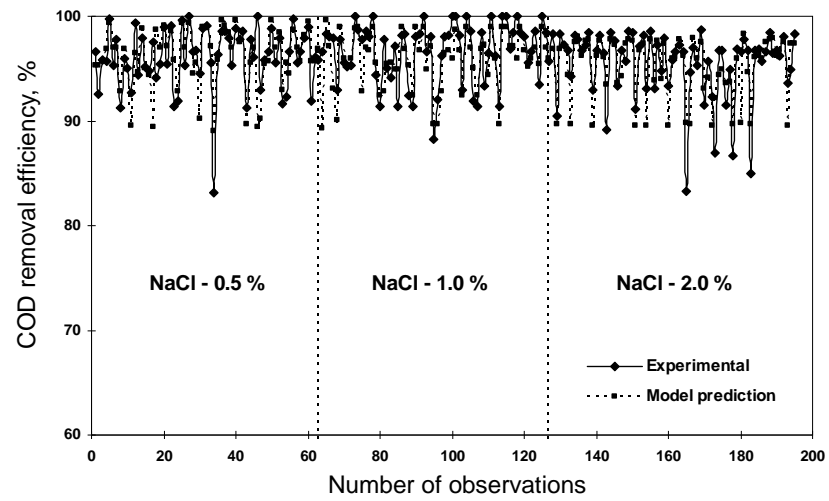

(a)

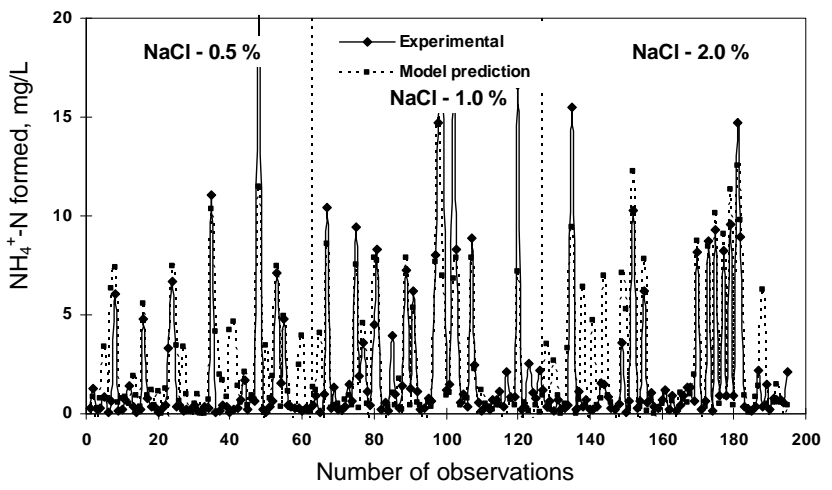

(c)

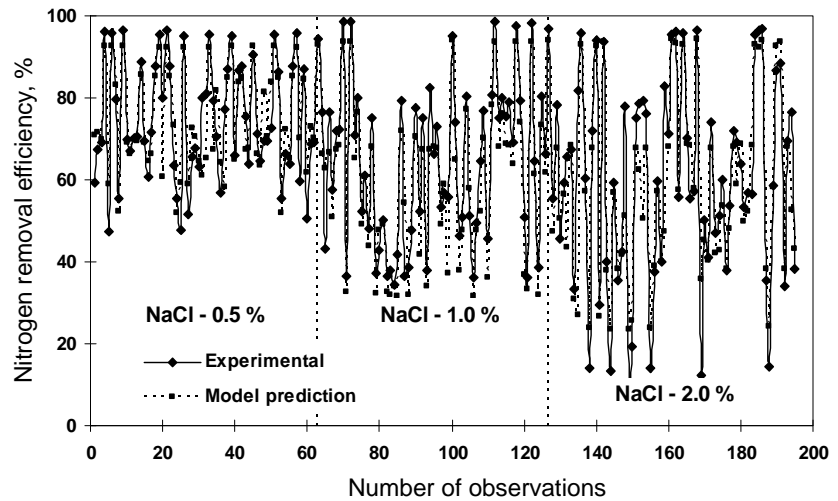

(b)

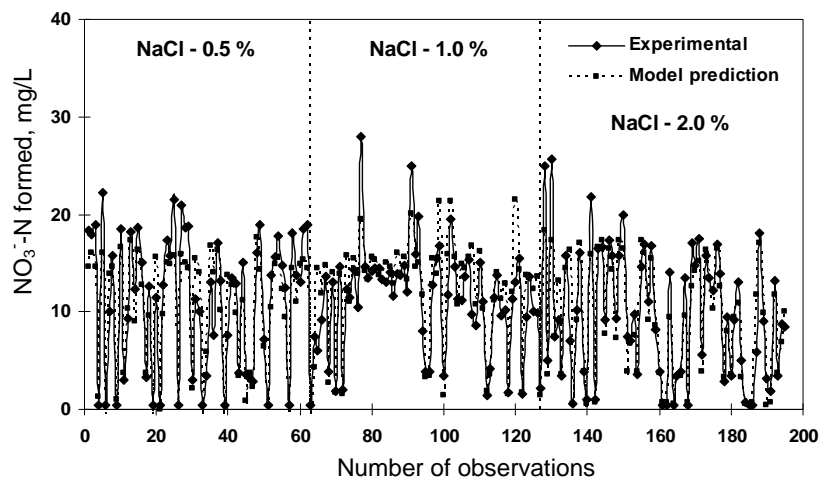

(d)

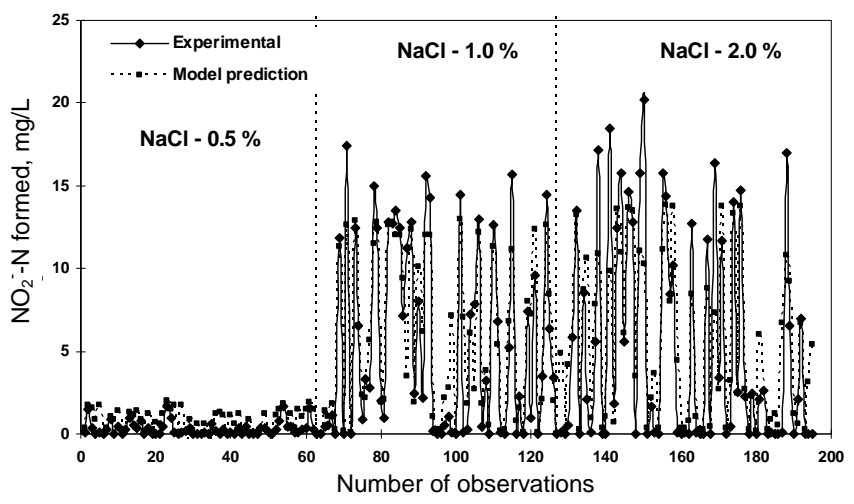

(e)

Figure 7. Predictive capability of the ANN model during network testing.

in influencing nitrogen removal and in formation of $\mathrm{NH}_{4}{ }^{+} \mathrm{N}$, $\mathrm{NO}_{3}{ }^{-}-\mathrm{N}$ and $\mathrm{NO}_{2}{ }^{-}-\mathrm{N}$ while aeration time influences the $\mathrm{COD}$ removal efficiency. It is well known that, under aerobic condition, the $\mathrm{NH}_{4}{ }^{+}-\mathrm{N}$ trend is more relevant than that of $\mathrm{NO}_{3}{ }^{-}-\mathrm{N}$ for nitrogen removal process control (Luccarini et al., 2002). In this study, salt concentration appears to be less significant and sensitive in affecting the COD removal efficiency, because the microbes were well acclimatized over a period of few months under high saline conditions prior to the experimental investtigation. However based on experimental values it was found that the removal efficiencies of nitrogen were lowered under increasing salt concentrations in the reactor. This could be further attributed to depletion of carbon source that made complete denitrification impossible. The strong influence of the values of MLSS was due to the variation of MLSS with operating time. The salt concentration had its strongest effect on $\mathrm{NO}_{2}{ }^{-} \mathrm{N}(0.1546)$, while the aeration time (0.2477) had high in- fluence on the COD removal. Furthermore, based on this data driven modeling approach and sensitivity analysis it can be concluded that the most critical factors affecting the performance of the reactors under saline conditions are MLSS concentration followed by aeration time and influent COD con- 
centration.

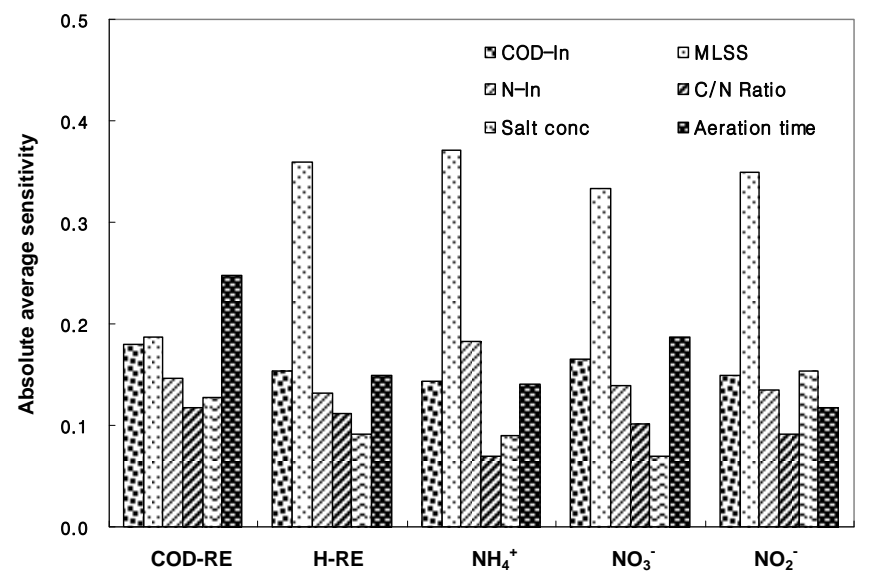

Figure 8. Sensitivity analysis of input parameters.

\section{Conclusions}

The following conclusions are based on the results of the data collected from three simultaneously operated SBRs and their performance modeling using neural networks:

1. The four step (anoxic/aerobic/anaerobic/oxic) SBR process showed high steady state organic removal efficiencies $(>$ $80 \%$ ), while the nitrogen removal efficiencies varied largely ( $\mathrm{NaCl}-0.5 \%$ : $25 \sim 99 \%$, NaCl-1\%: $25 \sim 98 \%$ and $\mathrm{NaCl}-2 \%$ : $10 \sim 98 \%$ ) with salt concentrations. The decrease in performance can be attributed to continual stress of the sludge microbes induced under saline environments.

2. The results from ANN based data driven modeling shows that the SBR performance (total nitrogen removal efficiency, COD removal efficiency $\mathrm{NH}_{4}{ }^{+}-\mathrm{N}, \mathrm{NO}_{3}{ }^{-}-\mathrm{N}$ and $\mathrm{NO}_{2}{ }^{-}-\mathrm{N}$ ) can be predicted with high confidence interval (95\%) using simple input design and operational parameters (influent COD, nitrogen concentrations, salt, MLSS concentrations, aeration time and $\mathrm{C} / \mathrm{N}$ ratio). The model was adequately trained with the lab scale SBR data and tested with a separate data set.

3. The suitable network architecture of the model was determined through statistically designed factorial design of experiment simulations. The computed correlation coefficient $(\mathrm{R})$ and root mean squared error (RMSE) values for the test data set show high correlation between the predicted and measured performance values. The best network topology was found to be 6-12-5, achieved at low learning rate (0.1), low momentum (0.1) and a training count of 50000.

The robustness of the ANN was further explored with a sensitivity analysis of the input parameters which showed that MLSS concentration and aeration time were the most critical factors affecting long term reactor performance. The results from this study could be used a supportive database to assess, monitor and design control strategies for SBR operation under saline conditions.
Acknowledgments. The authors would like to gratefully thank the Ministry of Maritime Affairs \& Fisheries, South Korea for supporting this research work (Grant MNF-12004001-2-2-SB010).

\section{References}

Antoniou, P., Hamilton, J., Koopman, B., Jain, R., Holloway, B., Lyberatos, G. and Svoronos, S.A. (1990). Effect of temperature and $\mathrm{pH}$ on the effective maximum specific growth rate of nitrifying bacteria, Water Res., 24(1), 97-101, doi:10.1016/0043-135 4(90)90070-M.

APHA (1995). Standard Methods for the Examination of Water and Wastewater, 19th Edition, Washington, DC.

Artan, N., Orhon, D. and Baykal, B.B. (1990). Implication of the task group model-I. The effect of initial substrate concentration, $\mathrm{Wa}$ ter Res., 24(10), 1251-1258, doi:10.1016/0043-1354(90)90049C.

Box, G.E.P., Hunter, W.G. and Hunter, J.S. (1978). Statistics for Experimenters, Wiley, New York.

Cho, B.C., Liaw, S.L., Chang, C.N., Yu, R.F., Yang, S.J. and Chiou, B.R. (2001). Development of a real-time control strategy with artificial neural network for automatic control of a continuousflow sequencing batch reactor, Water Sci. Technol., 44, 95-104.

Cinar, C., Hasar, H. and Kinaci, C. (2006). Modeling of submerged membrane bioreactor treating cheese whey wastewater by artificial neural network, J. Biotechnol., 123(2), 204-209, doi:10.101 6/j.jbiotec.2005.11.002.

Cote, M., Grandijean, B.P.A., Lessard, P. and Thibault, J. (1995). Dynamic modelling of the activated sludge process: Improving prediction using neural networks, Water Res., 29(4), 995-1004, doi:10.1016/0043-1354(95)93250-W.

Dahl, C., Sund, C., Kristensen, G.H. and Vredenbregt, L. (1997). Combined biological nitrification and denitrification of high-sali nity wastewater, Water Sci. Technol., 36(2-3), 345-352, doi:10.1 016/S0273-1223(97)00407-1.

Dangcong, P., Yi, W., Hao, W. and Xiaochang, W. (2004). Biological denitrification in a sequencing batch reactor, Water Sci. Technol., $50,67-72$.

Dincer, A.R. and Kargi, F. (2001). Salt inhibition kinetics in nitrification of synthetic saline wastewater, Enz. Microbial. Technol., 28 (7-8), 661-665, doi:10.1016/S0141-0229 (01)00312-X.

Elias, A., Berastegi, I., Arias, R. and Barona, A. (2006). Neural networks as a tool for control and management of a biological reactor for treating hydrogen sulphide, Bioprocess Biosyst. Eng., 29(2), 129-136, doi:10.1007/s00449-006-0062-3.

Furumai, H., Kazmi, A.A., Fujita, M., Furuya, Y. and Sasaki, K. (1999). Modeling long term nutrient removal in a sequencing batch reactor, Water Res., 33(11), 2708-2714, doi:10.1016/S004 3-1354(98)00470-9.

Ganesh, R., Balaji, G. and Ramanujam, R.A. (2006). Biodegradation of tannery wastewater using sequencing batch reactor: Respirometric assessment, Biores. Technol., 97(15), 1815-1821, doi:10.1016/j.biort ech.2005.09.003.

Gontarski, C.A., Rodrigues, P.R., Mori, M. and Prenem, L.F. (2000). Simulation of an industrial wastewater treatment plant using artificial neural networks, Comput. Chem. Eng., 24(2), 1719-1723, doi:10.1016/S0098-1354(00)00449-X.

Haykin, S. (1994). Neural Networks: A Comprehensive Foundation, Macmillan College Co., New York.

Henze, M., Grady, C.P.L., Gujer, W., Marais, G.V.R. and Matsuo, T. (1987). Activated Sludge Model No 1. IAWPRC Scientific and Technical Report No 1, London, England.

Hoskins, J.C. and Himmelblau, D.M. (1988). Artificial neural network models of knowledge representation in chemical engineering, Comput. Chem. Eng., 12(9-10), 881-890, doi:10.1016/009 8-1354(88)87015-7. 
Ibrahim, G. and Abasaeed, A.E. (1995), Modelling of sequencing batch reactors, Water Res., 29(7), 1761-1766, doi:10.1016/0043-1 354(94)00317-Z.

Kargi, F. and Dincer, A.R. (1997). Biological treatment of saline wastewater by fed-batch operation, J. Chem. Technol. Biotechnol., 69, 167-172.

Lee, D.S. and Park, J.M. (1999). Neural network modeling for online estimation of nutrient dynamics in a sequentially operated batch reactor. J, Biotechnol., 75(2-3), 229-239, doi:10.1016/S01 68-1656(99)00171-6.

Luccarini, L., Porra, E., Spagni, A., Ratini, P., Grilli, S., Longhi, S. and Bortone, G. (2002). Soft sensors for control of nitrogen and phosphorous removal from wastewaters by neural networks, Water Sci. Technol., 45, 101-107.

Maier, H.R. and Dandy, G.C. (1998). The effect of internal parameters and geometry on the performance of back-propagation neural networks: An empirical study, Environ. Model. Soft., 13(2), 193-209, doi:10.1016/S1364-8152(98)00020-6.

Maier, H.R. and Dandy, G.C. (2001). Neural network based modelling of environmental variables: A systematic approach, Math. Comput. Model., 33(6-7), 669-682, doi:10.1016/S0895-7177(00) 00271-5.

Montgomery, D.C. (1991). Design and Analysis of Experiments, 3rd Edition, Wiley, New York.

Moussa, M.S., Lubberding, H.J., Hooijmans, C.M., van Loosdrecht, M.C.M. and Gijzen, H.J. (2003). Improved method for determination of ammonia and nitrite oxidation activities in mixed bacterial cultures, Appl. Microbiol. Biotechnol., 63(2), 217-221, doi: 10.1007/s00253-003-1360-1.

Moussa, M.S., Hooijmans, C.M., Lubberding, H.J., Gijzen, H.J. and van Loosdrecht, M.C.M. (2005). Modelling nitrification, heterotrophic growth and predation in activated sludge, Water Res., 39(20), 5080-5098, doi:10.1016/j.watres.2005.09.038.

Orhon, D., Cimist, T. and Tunay, O. (1986). Substrate removal mechanism for sequencing batch reactors, Water Sci. Technol., 18, 21-33.

Panswad, T. and Anan, C. (1999). Impact of high chloride wastewater on anaerobic/anoxic/aerobic process with and without inocula- tion of chloride acclimated bacteria, Water Res., 33(5), 11651172, doi:10.1016/S0043-1354(98)00314-5.

Rumelhart, D.E., Hinton, G.E. and Williams, R.J. (1986). Learning internal representations by error propagation, in D.E. Rumelhart, J.L. McClelland and the PDP Research Group (Eds.), Paralled Distributed Processing. Explorations in the Microstructure of Cognition. Volume 1: Foundations, The MIT Press, Cambridge, MA, pp.318-362.

Shahaf, G. and Marom, S. (2001). Learning in networks of cortical neurons, J. Neurosci., 21 (22), 8782-8788.

Stephanopoulos, G. and San, K.Y. (1984). Studies on on-line bio-reactor identification, Biotechnol. Bioeng., 26, 1176-1188, doi:10.100 2/bit.260261006.

Tilche, A., Bacilieri, E., Bortone, G., Malaspina, F., Piccinini, S. and Stante, L. (1999). Biological phosphorous and nitrogen removal in a full scale sequencing batch reactor treating piggery wastewater, Water Sci. Technol., 40(1), 199-206, doi:10.1016/S0273-1 223(99)00385-6.

Uygur, A. and kargi, F. (2004). Salt inhibition on biological nutrient removal from saline wastewater in a sequencing batch reactor, Enz. Microbial. Technol., 34(3-4), 313-318, doi:10.1016/j.enzmi ctec.2003.11.010.

Uygur, A. (2006). Specific nutrient removal rates in saline wastewater treatment using sequencing batch reactor, Process Biochem., 41(1), 61-66, doi:10.1016/j.procbio.2005.03.068.

Zhao, H. and Kummel, M. (1995). State and parameter estimation for phosphorus removal in an alternating activated sludge process, $J$. Process Control, 5(5), 341-351, doi:10.1016/0959-1524(95)000 06-C.

Zhao, H., Hao, O.J. and McAvoy, T.J. (1999). Approaches to modeling nutrient dynamics: ASM2, simplified model and neural nets, Water Sci. Technol., 39(1), 227-234, doi:10.1016/S0273-12 23(98)00788-4.

Zurada, J.M., Malinowski, A. and Cloete, I. (1994). Sensitivity analysis for minimization of input data dimensions for feed forward neural network, in IEEE International Symposium on Circuits and Systems, London, pp. 447-450. 